\title{
Crime Mapping in Nigeria Using GIS
}

\author{
Toju Francis Balogun*, Henry Okeke, Christain Ifanyin Chukwukere \\ Department of Geography and Regional Planning, University of Benin, Benin City, Nigeria \\ Email: "tobalogun@yahoo.com
}

Received 10 July 2014; revised 8 August 2014; accepted 5 September 2014

Copyright (C) 2014 by authors and Scientific Research Publishing Inc.

This work is licensed under the Creative Commons Attribution International License (CC BY).

http://creativecommons.org/licenses/by/4.0/

(c) (j) Open Access

\begin{abstract}
This paper first examines crime situation in Benin metropolis using questionnaire to elicit information from the public and the police. Result shows that crime is on the rise and that the police are handicapped in managing it because of the obsolete methods and resources at their disposal. It also reveals that members of the public have no confidence in the police force as $80 \%$ do not report cases for fear of exposure to the informant to the criminal. In the light of these situations, the second part of the paper looks at the possibility of utilizing GIS for effective management of crime in Nigeria. This option was explored by showing the procedural method of creating 1) digital landuse map showing the crime locations, 2) crime geo-spatial database, and 3) spatial analysis such as query and buffering using ILWIS and ArcGIS software and GPS. The result of buffering analysis shows crime hotspots, areas deficient in security outfit, areas of overlap and areas requiring constant police patrol. The study proves that GIS can give a better synoptic perspective to crime study, analysis, mapping, proactive decision making and prevention of crime. It however suggests that migrating from traditional method of crime management to GIS demands capacity building in the area of personnel, laboratory and facilities backed up with policy statement.
\end{abstract}

\section{Keywords}

Crime, Hotspot, Geospatial Data, Database Design, Conceptual Modeling, Logical Design, Physical Design, Entity Relationship, Relationship Enforcement

\section{Introduction}

Crime is an act, default or conduct, prejudicial to the community, the commission which, by law, renders the person responsible to punishment by a fine, imprisonment or other penalty [1]. The scenario of crime in Nigeria disregards class distinction in the society, as both high (haves), and low (have nots), experienced similar and equal visitation of the hoodlums from time to time. The resultant tragedy, suffering, colossal loss and distress,

"Corresponding author. 
occasioned by those inimical visits, have been pervasive and had left an indelible mark on our national psyche and societal tranquility. Worse still is the fact that the law enforcement agencies are yet to be computerized for effective record keeping, analysis of cases, easy reference cum retrieval and storage of information to help strategize and adequately plan the combating and eradication of crimes in general. As an entity, crime has spatial attributes, i.e. location, time and process. In essence, availability and quick access to timely and up-to-date spatial information about crime-prone areas, to the law enforcement agencies, will in no small way contribute to effective policing of the entire state. Policing methods in Nigeria are still manual and un-automated. The old filing system of record-keeping is still in use. This limits the force from having the technological edge over the ever increasing technology sophistication of the criminals.

Crime mapping has long been an integral part of the process known today as crime analysis. The use of maps in crime study has been traced back to at least the year 1900 (New York City Police Department). Most developed nations have migrated from the "pin on maps" to the use of computer GIS. Unfortunately, most of the developing nations, including Nigeria, still utilize analog and outdated file systems. In most cases, police operations are carried out based on intuition, tip-off information and the simple "trial-and-error" method. Furthermore, the old pin maps were useful for showing where crimes occurred, but they had serious limitations because as they were updated, the prior crime patterns were lost. The maps being analogs are usually not easy to manipulate. In addition, pin-maps could be quite difficult to read when several types of crimes, usually represented by pins of different colours, are mixed together. Pin maps occupied a lot of space, wasted a lot of time, and were incapable of developing a logical, national database. Based on these disadvantages, the need to carry out research on a better way to map crime and manage it becomes paramount. This study therefore seeks to explore the capability of GIS in crime mapping, using Benin metropolis as a case study.

\section{Study Area}

Based on the city historical, political, administrative and nodal attributes, Benin City (Figure 1) has witnessed an

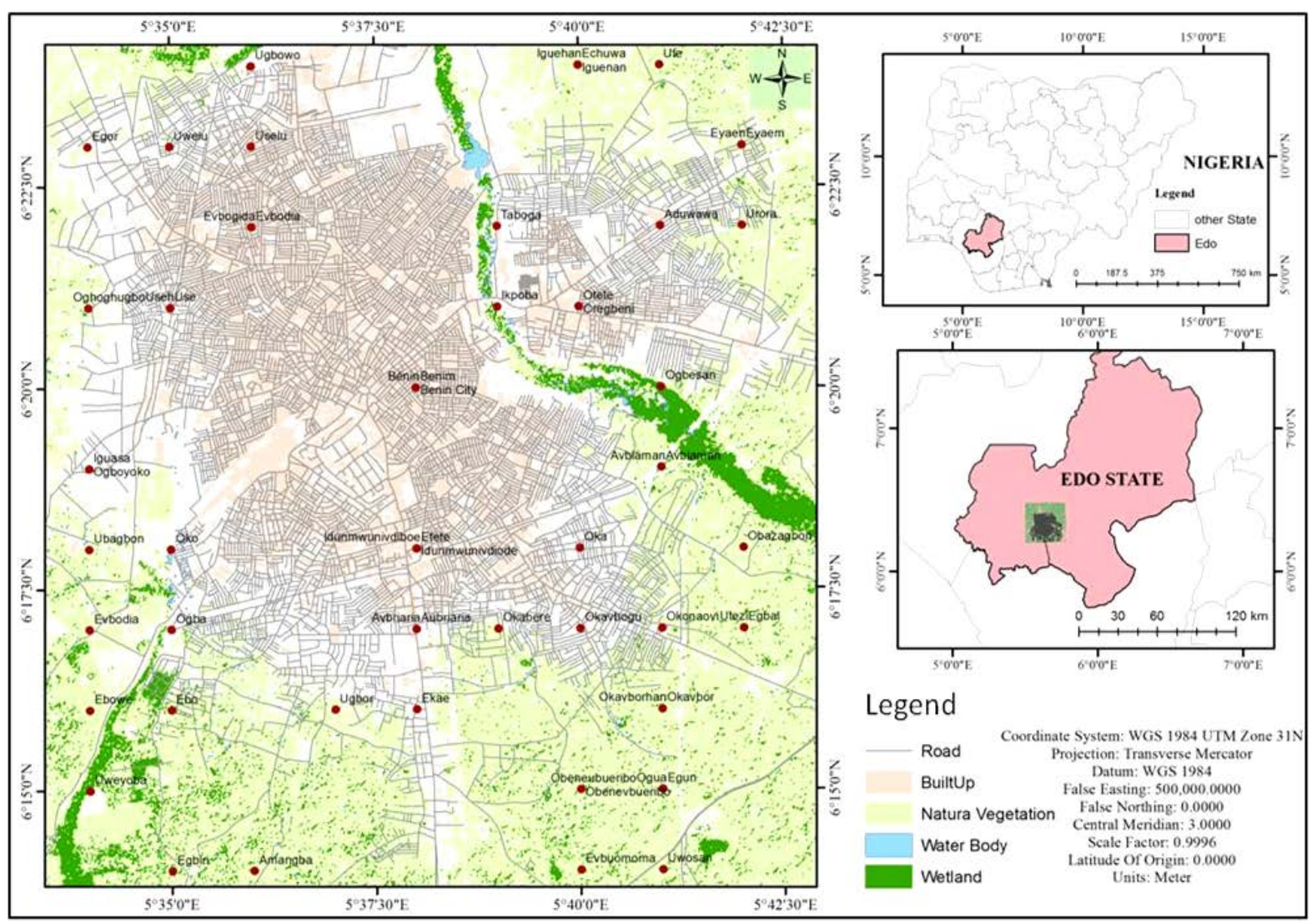

Figure 1. Study area. 
arithmetic progression in growth, size, population and civilization. Simultaneously it has also witnessed a corresponding and progressive crime growth. In Benin metropolis, crime is high, occurring in different forms, thus stimulating the need to tackle it before it expands beyond control. It is no longer hidden that the cities are conducive settings for criminal activities, since it provides the anonymity required for individual crime, and the space for a specialized and organized underworld. The increasing social sophistication and modernization of the country, the growing inequality, and the continuous rise in unemployment (especially among young school leavers and university graduates) have greatly accentuated urban crimes in recent times. Kidnapping, for instance, is on the increase in Benin City. Despite trying their best, the law enforcement agencies are becoming frustratingly helpless as the criminals become more sophisticated on a daily basis. As a result, the citizens daily grapple with the fear of the unknown and insecurity of lives and property with little or no hope of remedy. Unfortunately, at present, there is little or no application of even the inadequate pin-on-maps in some stations in Benin City, let alone the use of GIS. The non-application of GIS and geo-database in the fight against crime in this technological age is costly and counter-productive [2].

\section{Conceptual Framework}

Crime theories are critical for useful crime mapping because they aid in the interpretation of data [3] and provide guidance as to what actions are most appropriate. Therefore, understanding how crime theories account for hotspots is critical. Several theories of crime and disorder concentrations (hotspots) exist. Crime theory explains different types of crime phenomena that occur at different geographic levels. Each level requires different units of analysis for the things being examined. One can think of units as corresponding to the geographic area being depicted on map points, lines or polygons [4]. Some theories explain point concentration of crime while others help explain linear concentrations of crime or hotspot crime polygons.

Urban crime has measurable spatial and temporal distribution that requires urgent attention of the specific arm of government responsible for maintaining law and order [5] which is usually the police and the judiciary. Knowing "what" is "where", "where" is "what" and "when", is the task of GIS, the need for which therefore cannot be overemphasized. Crime (what) is a spatial entity which has a geographical location (where) and a time (when) it was committed. With the spatial and non-spatial integration capability of GIS, various crime prone areas can be mapped to provide timely and up-to-date information that is infinitely superior to the normal paper records of events by the law enforcement agencies.

Crime is a human phenomenon; therefore its distribution in space is not random. Crime analysis is important because it helps to identify the different geographic patterns in criminal behavior [6]. GIS software can create a single visual output that combines multiple data layers into a meaningful output. The analysis between crime and other factors, for example roads, housing, police station, and other structures, can lead to the knowledge of place and crime relationship based on the conditions considered. GIS allows integration and analysis of data to identify, apprehend and prosecute suspects; it aids more proactive behaviour through effective allocation of resources and better policy setting [7]. For example, thematic maps could be used to predict likely sensitive points/areas in hotspot area. Data on surface communication, telephone communication and demographic pattern can all be used to predict sensitivity of a locality in relation to a given time [8].

GIS is pervasive in its use, ranging from identification of illicit cultivation of poppy seeds in Afghanistan with satellite imageries [9] to measuring the geographic displacement of drug offenders [10] and monitoring the effects of law enforcement strategies on nuisance bar activity [11]. The history of crime mapping dates back to 1830 [12] when sociologists and criminologists had written hundreds of spatially oriented studies of crimes and intelligences. These studies could be divided into three schools of thought: the cartographic/geographic school, the typological school, and the social ecology school [4] [13]-[15].

\section{Methodology}

Two methods were adopted in this study. The first was the administration of questionnaires. A total of 66 questionnaires were administered to the Police Public Relation Officers (PPRO) while a set of 250 questionnaires were administered to gather information from the member of the public. This was done to assess the crime situation in the metropolis. The second was a stepwise method (Figure 2) of how GIS could be used to manage crime using the spatial and attribute data collected from the field.

- Data on crimes and their locations as well as the location/capacity of various police stations. 


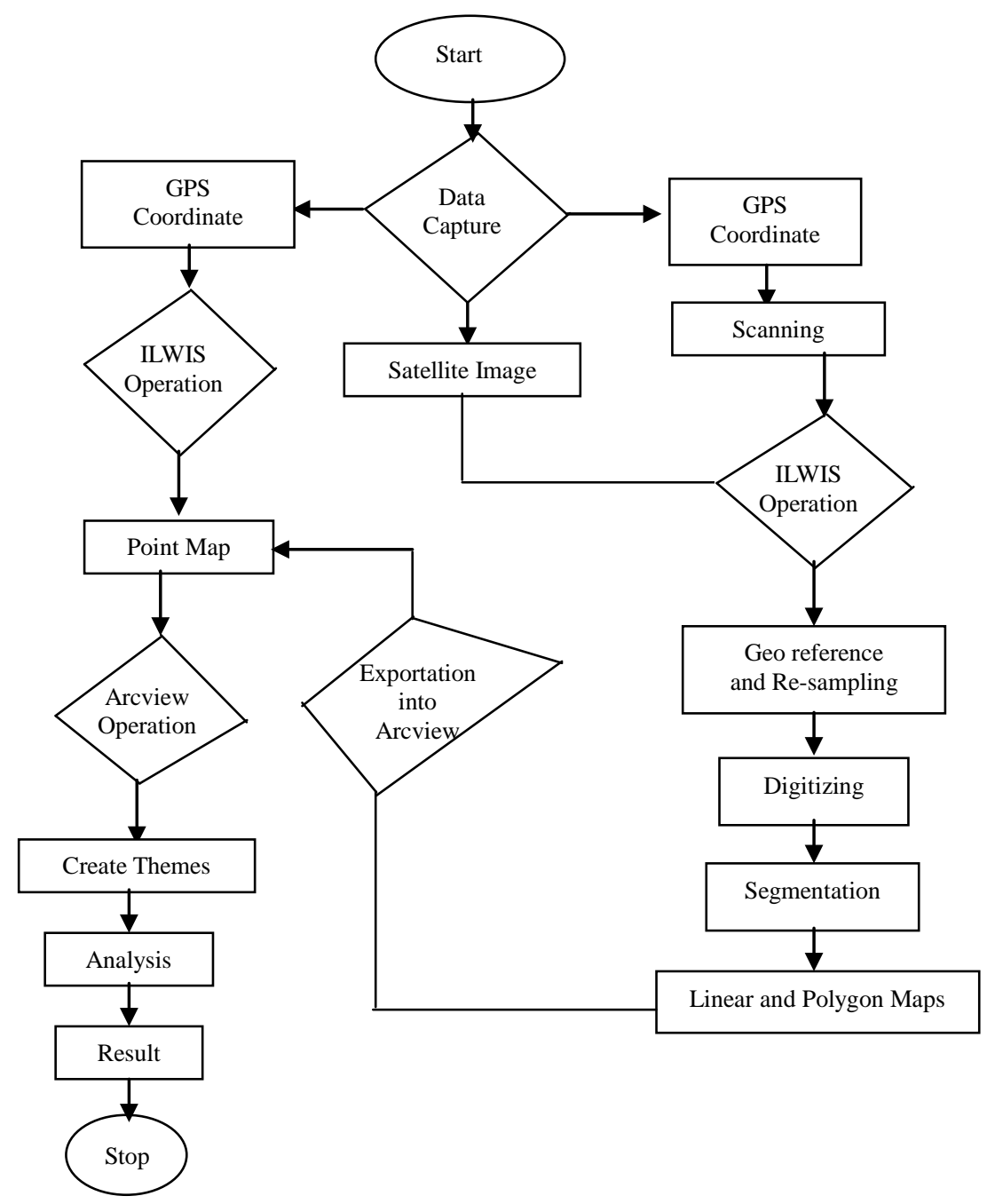

Figure 2. Flow chart for data processing.

- Data on drug related crimes and their locations from the National Drug Law Enforcement Agency.

- 2006 census figures, housing data and satellite images from the National Population Commission.

- Landuse and road guide maps from the Ministry of Lands and Survey.

A hand held high precision ( \pm 5 m) GPS (Gamin GPS $12 \times$ L, 12 channel) and a digital camera (Nikon 4200 mega pixels) for real time pictorial coverage of the hotspots and police station (where possible).

\section{Result and Discussion}

Figure 3 shows that $67 \%$ of the respondents are above 25 years. $23 \%$ are married, $61 \%$ single and $16 \%$ others (separated/widow-widower). All the respondents have lived within the study area for more than 3 years, meaning that by virtue of their long stay they are acquainted with their immediate environment as far as crime is concerned. In terms of occupation, $49 \%$ of the respondents are students mostly from tertiary institutions and this group is a very volatile set, on the grounds that they constitute the bulk of the non-working population and are subject to all sorts of possible incriminating activities as a result of needs, peer activities and age. The other groups are employed in one form of occupation or the other.

\subsection{Crime Rate and Pattern}

Result shows that $97 \%$ of respondents have knowledge of crime within the metropolis while Figure 4 shows 

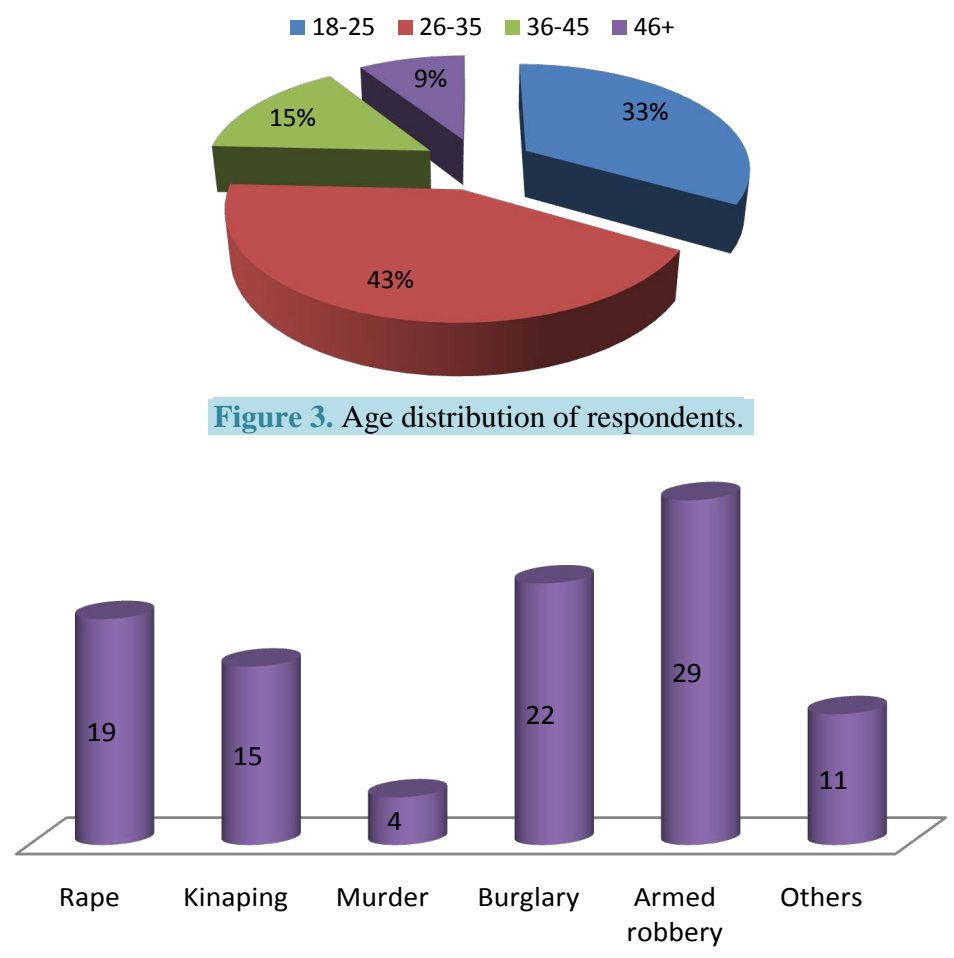

Figure 4. Prevalent types of crime in Benin City.

different types of crimes experienced in Benin metropolis. The analysis shows that robbery singly accounts for about one third (29\%) of the total number of identified crimes. This was closely followed by burglary (22\%), rape (19\%) kidnapping (15\%) murder (4\%) and others, which include pickpocketing (11\%). The implication of this result is that crime is endemic in the metropolis and as such, efforts should be directed at checkmating it.

81 percent of people who have been crime victims have knowledge of the location of police station (see Figure 5); $84 \%$ of the victims did not report crime incident to the police for a number of reasons (see Figure 6). Reasons provided for not reporting crime to the police include: the fear of being exposed by the police through connivance with criminals which is common; perceived police often apparent insensitivity to duty, and the police lack of arms, intelligence, integrity and logistics to effectively combat crime in the metropolis.

It is not surprising therefore, that the effort to curb the menace of crime is still not receiving the needed support it deserves as most crimes are left unreported. The survey equally revealed that among those who have reported crime, only $19 \%$ agreed that the police always respond. $78 \%$ agreed that the police sometimes come to their rescue, while 3\% agreed that police never respond to distress calls (see Figure 7). The study also revealed that $42 \%$ of the respondents agreed that the police have carried out raids (particularly the Special Anti Robbery Squad (SARS)) as a way of combating crime while the rest $58 \%$ have different opinions. Sequel to the above, about $96 \%$ of the people have resorted to organized local security outfit know as "vigilante" while the rest have contracted local security outfits to prevent such crimes as robbery and burglary in their area. Regardless of the above measures, the research also revealed that crime rate is still on the increase especially with news of fresh attacks on banks, people, and even the police.

Interview with different police officers revealed that positive efforts are being made by the police to eradicate crime regardless of the many impediments it is faced with. These efforts translate into the following specific measures: Encouraging research into crime thorough investigation of crime; protecting the anonymity of informants; periodic publication of crime data; road block checking, periodic patrol, raid and arrest of suspects. In all these current efforts, there is no application of geo-information technology.

\subsubsection{Map Scanning and Conversion}

The first step is the conversion of the existing thematic road map covering the study area from analogue to digital. The road map was scanned in JPEG format in the Corel photo paint, and was exported into adobe photoshop 


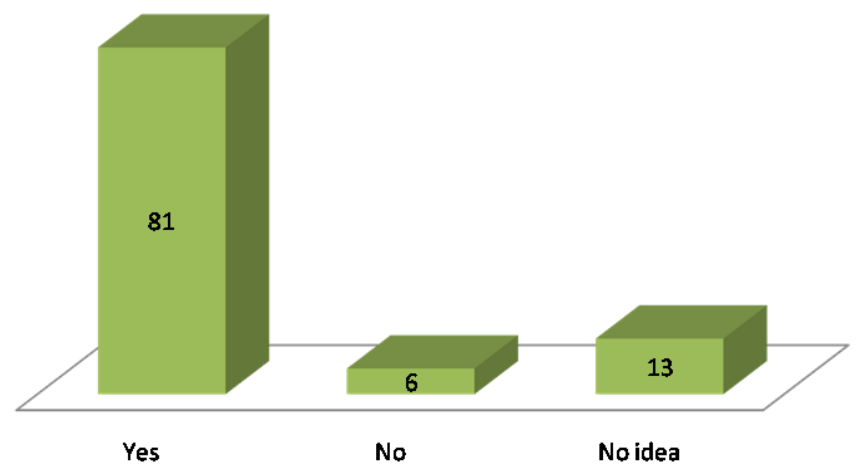

Figure 5. Knowledge of the location of police station.

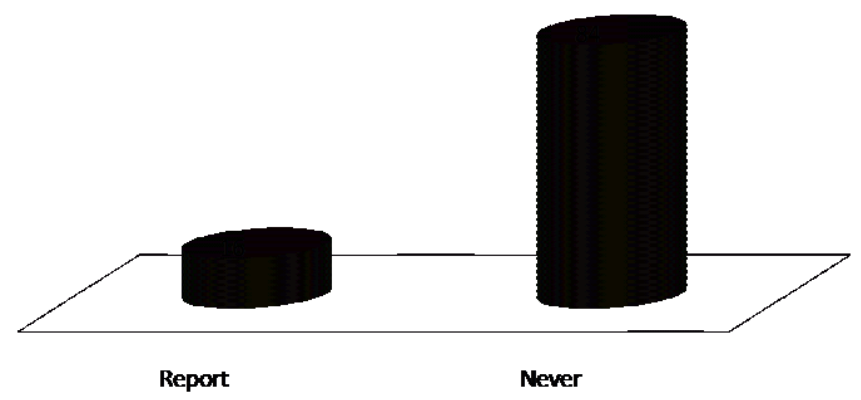

Figure 6. Crimes report to police.

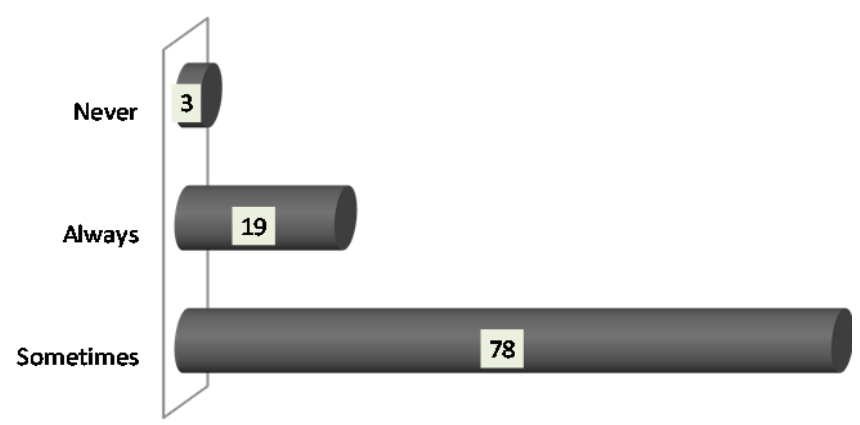

Figure 7. Police response to crime.

7 where it was converted to the TIF format that is compatible with ILWIS. After the conversion, the map in TIF format was imported into ILWIS environment for geo-referencing.

\subsubsection{Geo-Referencing}

The GPS gave UTM coordinates directly which was used for geo-referencing on the scanned image to bring a relationship between the scanned image to actual representation on the ground, using the point method of identifiable points on ground with GPS coordinates and its corresponding location on the map in ILWIS environment. The result of the geo-referencing gave a sigma of 0.0025 .

\subsubsection{Digitizing}

The scanned map was then resampled in ILWIS, using operations image processing. This was done in order to orient the map to the North. After geo-coding/resampling, the map was exported to Arcmap-Arcinfo environment where on-screen digitizing was carried out. Before the commencement of the digitizing, a geo-database was created in Arc-catalogue and also all the feature class and projection were specified. Editing was performed by zooming to check for overlap, hanging error, spaghetti error and to make sure the entire midpoint, vertex are well joined. 


\subsubsection{Creation of Point Map}

The GPS coordinates obtained were entered into Arcmap-Arcinfo environment through point map operation. Here domain class and name were created for each point. Two-point maps were created for the hotspots (red) and the other for the police station (black). The point map was now superimposed on the digitized road map. Some of the points fell outside the digitized area without the network. This calls for the satellite image so as to correct this error. The image was imported into ILWIS via geo-gateway using bands 7, 5, 4 for the false color composite enhancement, where linear features are better shown. The image was geo-referenced and re-sampled. A sub-map was then cut out to avoid loading the entire image all the time and to minimize space in the system. On screen digitizing of linear features in a separate layer was carried out on the image to update the digitized map. Note that only prominent features could be picked, such as the major roads and river. The minor roads could not be picked due to the low resolution of the satellite image. Editing was carried out for self-overlap and intersection. The two layers were merged through a glue operation and break dependence tool. A uniform coordinate system and domain name was required for this operation. The digitized map was now ready for importation into Arcmap environment where analysis was carried out.

\subsubsection{Database Design}

Database consists of some collection of persistent data that is used by the application systems of some given enterprise [16]. A database is a repository, capable of storing large amounts of data [17]. Geospatial data handling process entails a demand supply processing of a phenomenon (crime) in the world, applying (GPS) technology to acquire survey data, creating a (relational) database via choice of a model at the conceptual level, and applying technology, (software \& hardware) cum methodology on processing (analysis). The results are in form of report, tables, graphics, intelligent maps and database, which should be sharable concurrently by many users, possess optimized storage, has integrity and should be queried optimally. However, in the creation of database in the context of geo-informatics, the concept of space is not taken for granted. Space concept addresses the world around us and our immediate environment. A GIS database is made up of two parts: a) The components of a database, and b) the design phases of the database [18]. The two (a and b), are composed of five basic components, made up of geographic or location entities, non-geographic or attribute entities, topological relationship, enterprise rules and procedure to be followed. There are different phases in the creation of database which is followed in this work. These include the design phase, conceptual design, logical design and physical design phase.

\subsubsection{The Design Phase}

The design phase of the database has four parts, which are: 1) view of reality, 2) conceptual or data modeling, 3) data structure or logical design, and 4) physical design or file structure.

\subsubsection{View of Reality}

This is the mental abstraction of reality. It is the perception of the phenomena, as it actually exists, including all aspects, which may or may not be perceived by individuals. In this study, the reality as far as effective community policing is concerned, was abstracted. A vector representation scheme of the crime hotspots points and police station location (points) were therefore adopted as the primitive.

\subsubsection{Conceptual Design Phase}

The conceptual modeling is a human conceptualization of reality of the entire information content of the database. Here, the decision on how the views of reality will be presented in a simplified manner and satisfaction of the information requirements of the project must be made. The basic question here is, what method do you intend to implement in your ideal or view, without losing the originality of the reality? Thus, the question of what, when and where of phenomenon (crime) could easily be answered by GIS operation. In this study the basic entities identified are, police stations, settlements, crime spots, roads, local government area (or city area). These entities are conceptually related as schematized using Microsoft vision 2007 in the entity-relationship diagram (see Figure 8).

The identified terrain objects in a vector model are represented by point, lines and area objects. This geometric data of these objects are given in O dimension for police and crime hot points, ID for linear feature (road, rivers, streams) and 2D for area feature (boundary of police jurisdictions). In this case, the location data may be $\mathrm{xy}$ or $\mathrm{x}, \mathrm{y}, \mathrm{z}$. 


\subsubsection{Logical Data Model}

The relational data model which has an advantage of being amendable to structural query language (SQL) was adopted.

\subsubsection{Creating Relational Tables in Microsoft Access}

The relational tables were created, populated and relationship was enforced by the introduction of common keys which was either a primary or foreign to link the tables together. All these were done within Microsoft Access environment. See Figure 9 for the entered relationship among the tables.

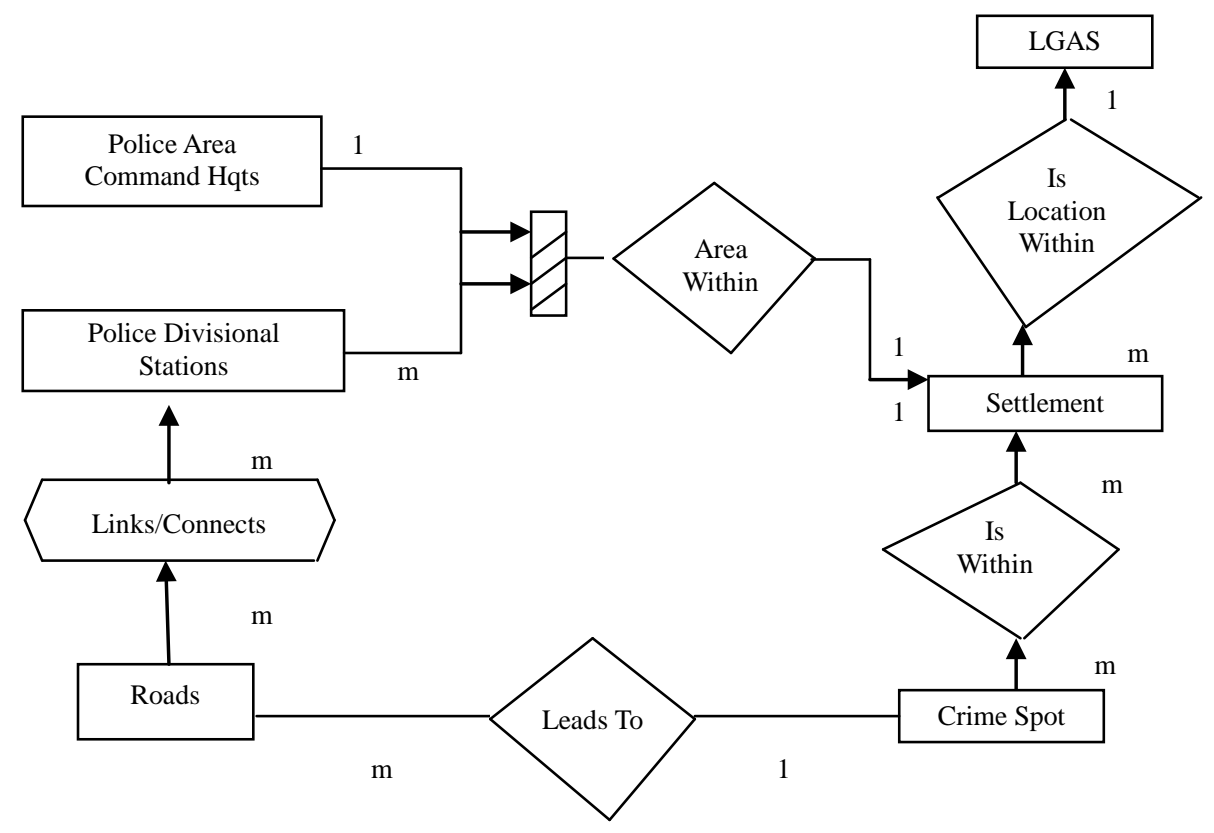

Figure 8. Entity relationship diagram.

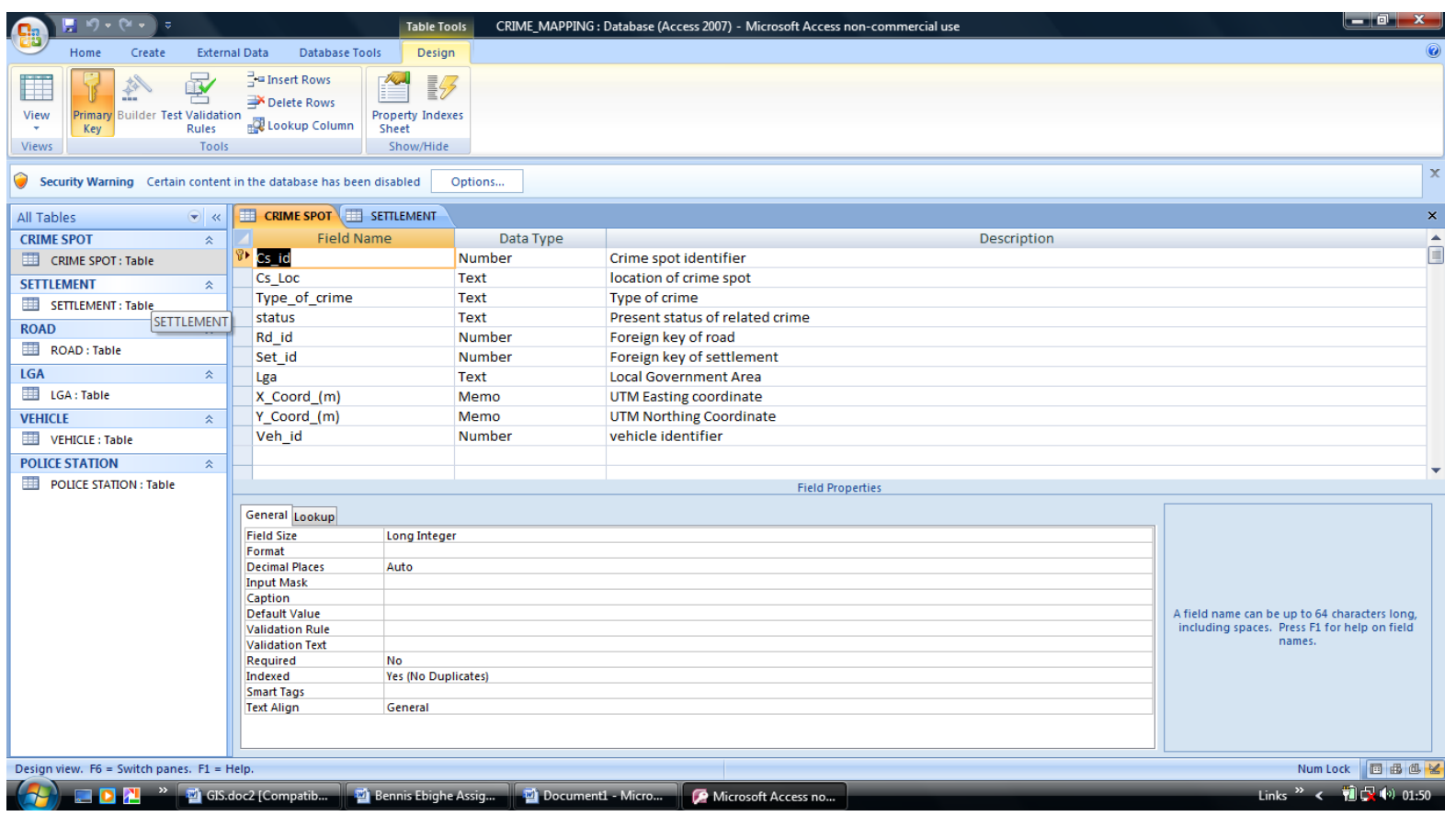

Figure 9. Relational database table created for crime spot in Microsoft Access. 


\subsubsection{Physical Model}

This defines the actual physical database scheme. The final stage is definition of the actual physical database scheme that will hold the database values. This is usually created using the DBMS software data definition languages. This model also specifies and addresses the issue of implementation hardware and software for the project study.

Analysis functions of GIS software use spatial and non-spatial attribute data to answer question about the real world. This aspect examines the spatial pattern of crime in Benin metropolis. To achieve the above, results of analysis were presented using a created database to visualize the various applicable route networks, proximity and other relationships between socio-economic activities. Executed analysis to accomplish the stated objectives include: buffer zone generation; crime distribution pattern; network analyses and spatial proximity of road.

\subsubsection{Crime Analysis}

Crime is a human phenomenon, generating data for it requires the integration of the people and the existing security outfits (police) within the geographical location where the study is carried out.

\subsubsection{Buffer Zone Generation, Queries and Crime Pattern Analyses}

Various queries were carried out to examine the spatial pattern of criminal activities in the metropolis so as to visualize and provide a useful suggestion on how to eradicate the menace of crime in the society. The following queries were carried out:

1) Single buffer (500 $\mathrm{m}$ ) around hotspots for robbery and rape.

2) Single buffer (500 m) around hotspots for burglary.

3) Single buffer (500 $\mathrm{m}$ ) around hotspots for cultism and rape.

4) Single buffering (500 $\mathrm{m}$ ) around hotspots for socio-economic activities.

An applicable geospatial analysis that can assist in crime management is buffer zone generation. This involves establishing a distance of equal radius around a phenomenon of interest to show its areas of influence based on specified parameters (the phenomenon of interest in this research refers to hotspots). Buffer or proximity analysis was used to map the identified impact zones (hotspots) in the metropolis where control of activities needs to be strengthened. A distance of $1 \mathrm{~km}$ was observed for the single distance buffers (Figure 10) to accentuate the immediate areas vulnerable to attack. Likewise, in the multiple distance buffers (Figure 11) the distance of $1 \mathrm{~km}$ (ring) was used. Results for buffer analysis:

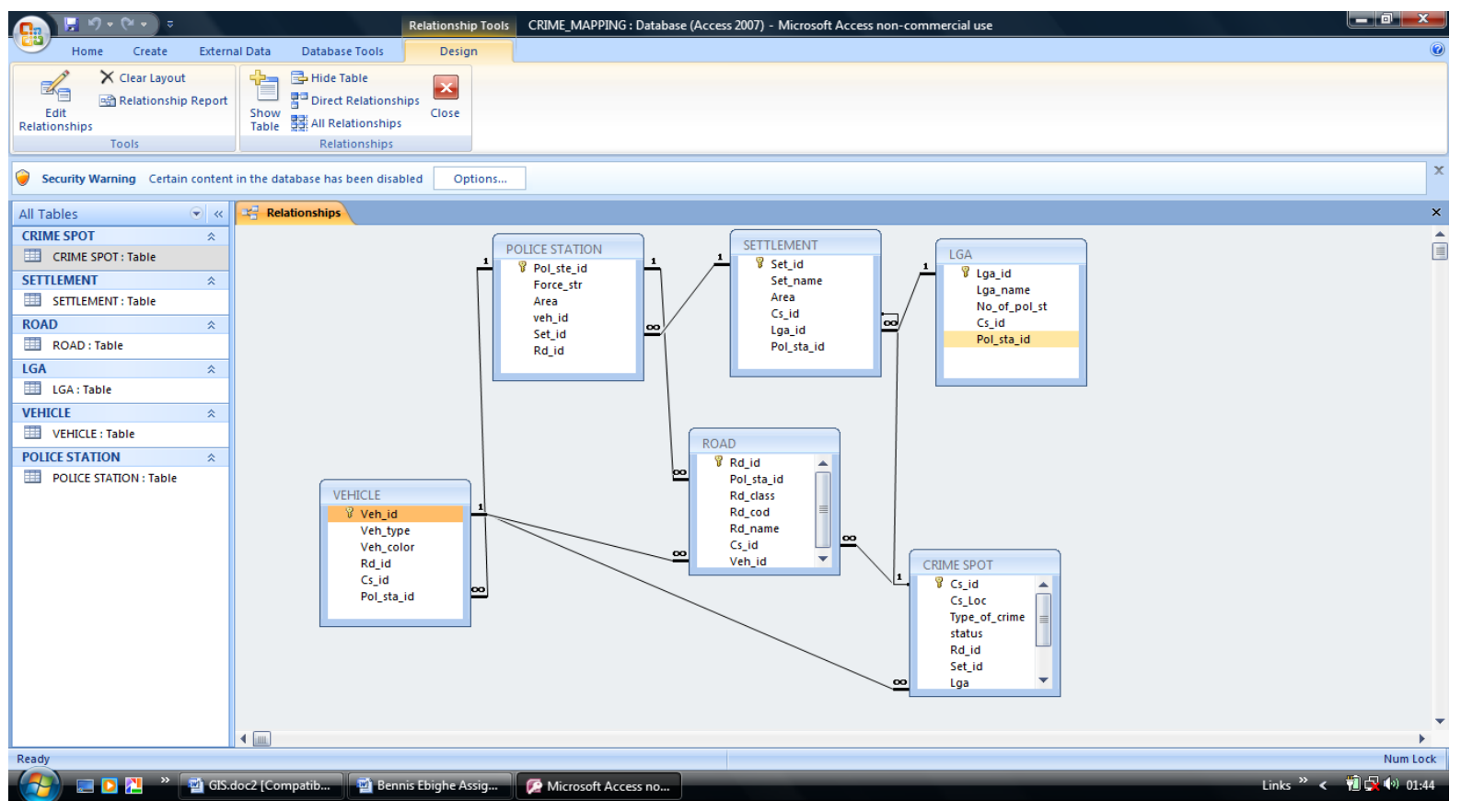

Figure 10. Relationship enforced among entities. 


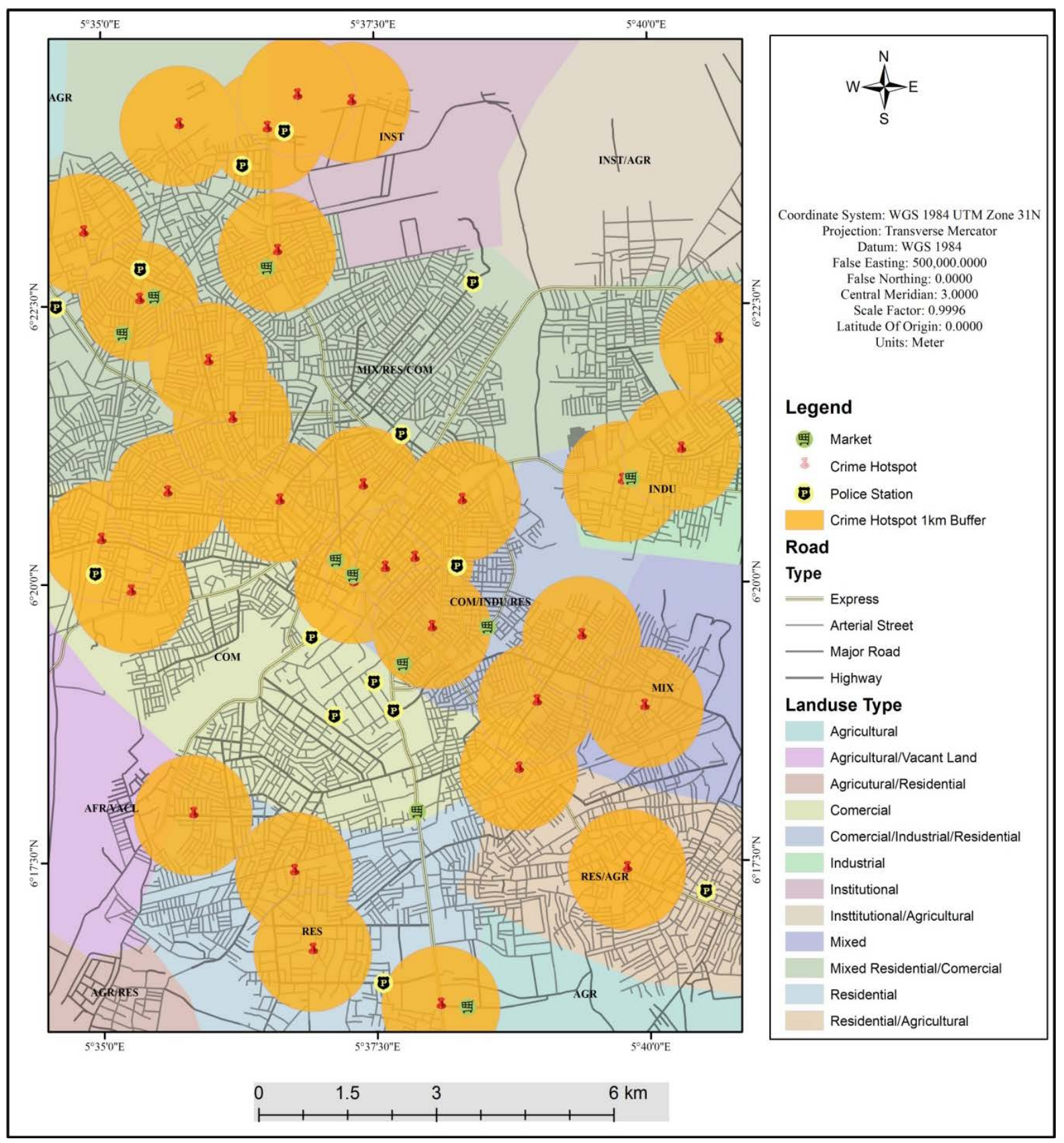

Figure 11. Single buffer of crime hotspot.

The single buffer (Figure 11) shows that most areas are highly vulnerable to different types of crimes. These areas include Oba Market and environs including Ogbe quarters, Eric, Asoro, Oka, Christ Apostolic road, Uwa primary school area, and Igbesammwan, St. Saviour, Faith way and Gapiona in GRA. Akpakpava, Oregbeni, Wire road, Uselu market area, Uwasota, Ugbowo BDPA housing estate, Osasogie near UBTH and Ekosodin Village near University of Benin.

The multiple buffering (Figure 12) shows that as one move further way from hotspots vulnerability to crime reduces especially at the north eastern. The area of overlap of hotspots buffer reveal high risk of crime in those areas. The fact that most police stations are located within the area of multiple overlap buffers shows that the police are not fully in control of the area under their jurisdiction. This calls for a change of mode of operation.

Most socio-economic activities such as banks and markets are co-located within or near most crime hotspots 


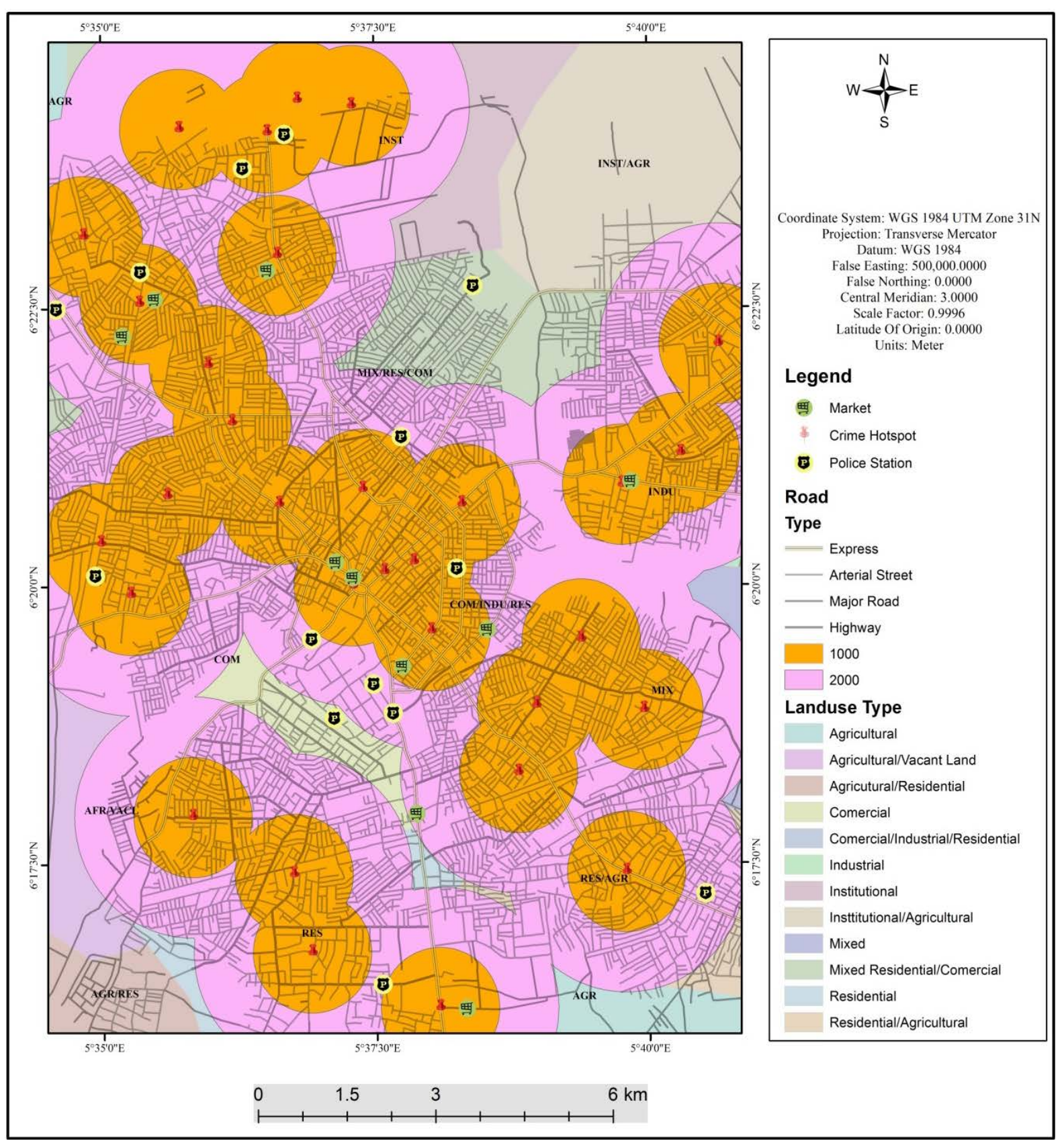

Figure 12. Multiple buffers of crime hotspot.

as shown in Figure 13. These activities location are of best interest to the public but they have also continued to attract criminals because of their site and functional peculiarities, financial status and economic relevance. Single buffer $(500 \mathrm{~m})$ around hotspot for burglary reveals that burglary combined with robbery are dominant around Sapele road new Santana market, Adolo college road in Ugbowo, Iwoghan at Ikpoba Hill, Etete in GRA, Ugbokum quarters, Sokponba road and St. Saviour. Field work shows that the nature of housing and the distance from police station contribute to the prevalence of burglary in those areas.

Our study reveals that cultism, robbery and rape are dominant in most areas in Benin metropolis. The study further reveals that areas such as Uwelu, Uwasota, Ekosodin where most University of Benin students reside, Nitel Junction at Ikpoba Hill along Benin-Auchi road, and Uwa primary School are prone to these crimes.

Utilizing the different findings and output of the GIS analysis, the study has shown a lot about the nature of 


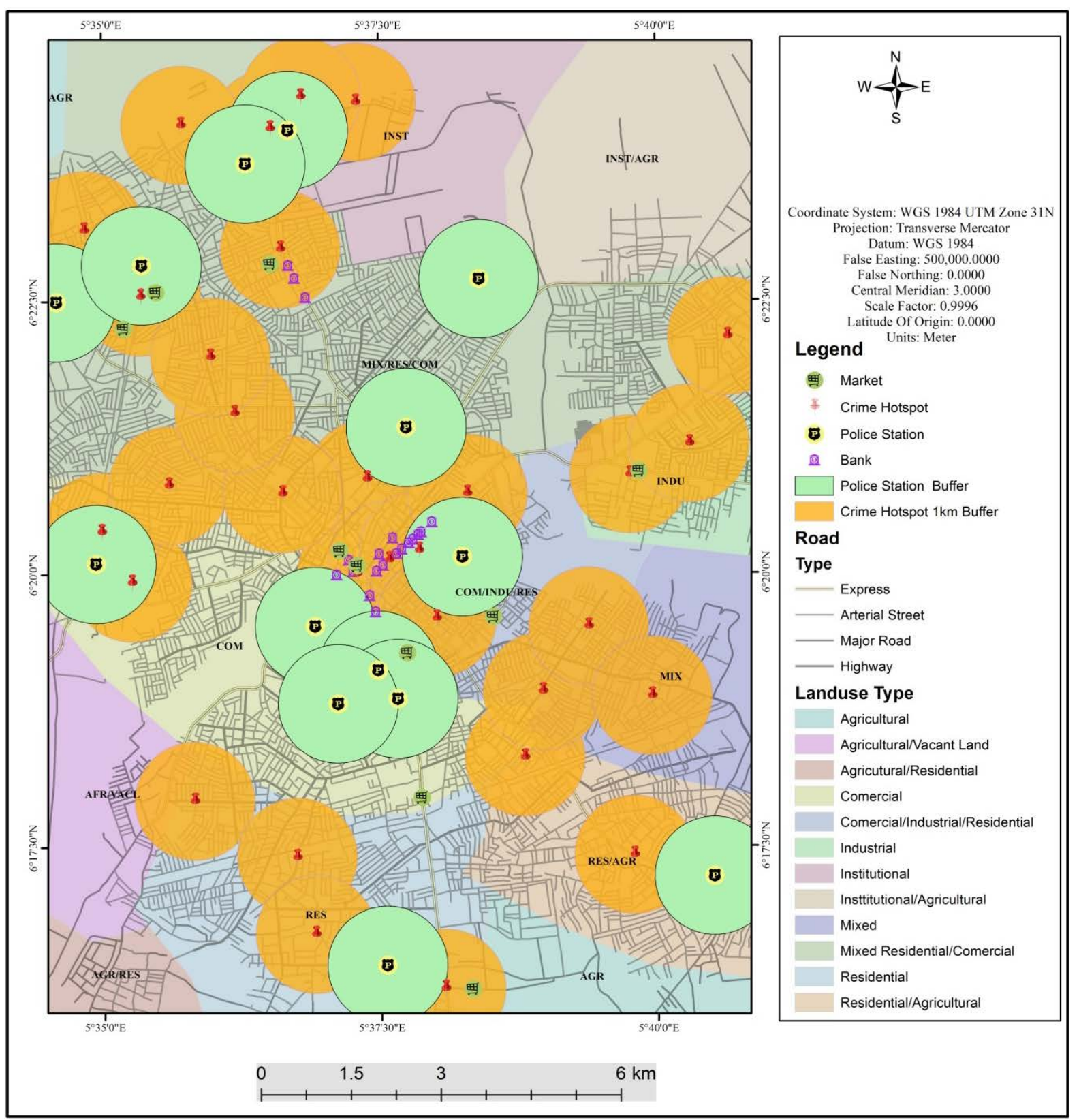

Figure 13. Buffer police station/crime hotspot in relation to other socio-economic activity.

crime in the study area. First the buffer around the police stations has shown areas of lack in terms of security outfit, and it has also shown the distance it takes a police to move from one hotspot to the other. Secondly, the areas with overlapping buffer suggest the need for constant patrol.

In the same vein, the situation described also reveals that police can be dispatched to hotspot strategically unlike the use of trial and error. More importantly, during the chase of a suspect, the route layer provided by GIS analysis can easily help in the apprehension of the suspect and generally in establishing a better crime fighting plan. Thirdly, the study has proved that GIS can give a better synoptic perspective to crime study, analysis, and mapping, thus acting as decision support system.

\section{Conclusions and Recommendations}

The study has attempted to operationalize the application and utilization of geographical information system in 
crime management and in security situation analysis for efficient community policing in Nigeria, using Benin as case study. The location of police station vis-à-vis police-public relation was observed to be very poor hence, the low report of crime incidents and suspects. The study also shows that armed robbery is the major crime in the city closely followed by burglary, rape, pick pocket, murder and other crimes. Combating crime, therefore, requires a well prepared police force with efficient manpower and a robust logistics which for now are absent. Record keeping is in analogue format which is inefficient in crime analysis. This situation is not good enough in the light of the modern day crime fighting and policing techniques. The benefits derived from using GIS technique in combating crime are considered enormous, hence it is recommended to the Nigerian Police Force for adoption without further delay. The proximity to crime hotspots shows some areas are more vulnerable to crime than the others.

Furthermore, the application of GIS in crime study will enable the creation of a "geo-database" to reduce redundancy, automate police field operation and increase the effectiveness of crime fighting in all ramifications. GIS uses automated means of detecting, analyzing and combating crime through the production and use of hardcopy and soft-copy guidable maps to analyze crime trends based on their location, types, or time of occurrence [19]. Crime mapping is used by analysts in law enforcement agencies to map, visualize, and analyze crime incident patterns. It helps law enforcement management to make better decision, target resources, and formulate strategies, as well as for tactical analysis such as crime forecasting. Mapping crime, using geographic information systems (GIS), allows crime analysts to identify crime hotspots, along with other trends and patterns.

It is concluded that for effective crime control and management in Nigeria, the security operatives should engage in the modern standard of policing by adopting and integrating GIS methodology as this will help the force to be proactive in their operations. Based on the response from the police and the result of the study, the following recommendations are proposed. There should be provision of GIS laboratory for data handling within the police information system, regular capacity building of police personnel based on the use of this geospatial technology should be considered seriously, provision of navigation vehicles and GPS facilities for effective tracking and acquisition of digital map for every city in different coverages and layers.

The Nigerian approach to crime control and management is still mundane and grossly inefficient to effectively combat the present day surge of crime. This is particularly worrisome in the midst of series of artificial intelligence, offered by sophisticated technologies, thus the recommendation for the use of GIS in preventing and managing crime in Nigeria. There is an urgent need to upgrade to a more advanced system of crime control by employing GIS facilities in crime mapping to improve the understanding of crime pattern in relation to roads, police stations, residence of offenders and also to identify jeopardy surfaces (hotspots) of crime in a locality. The use of GIS technology will be of great significance to the law enforcement agency, as it will serve as a tool for decision support system for policy makers by providing a frame work for improving quality of service delivery, and efficient policing, thus making the police react quickly and proactively. This will enhance safety of lives and properties as well as provide a favourable business environment within the nation.

\section{References}

[1] http://www.cps.gov.uk/publications/agencies/dv/gwent_info.html

[2] Eylon, L. (2004) GIS: A Powerful Weapon in the Fight against Crime. http://wwwgisvisionmag.com/feature/crime

[3] Eck, J. (2002) Preventing Crime at Places. In: Sherman, L., Farrington, D., Welsh, B. and MacKenzie, D.L., Eds., Evidence-Based Crime Prevention, Routledge, New York, 241-295.

[4] Harries, K. (1974) The Geography of Crime and Justice. In: Harries, Ed., Mapping Crime: Principle and Practical U.S. Department of Justice, Office of Justice Program, Washington D.C., 20531. https://www.ncjrs.gov/pdffiles1/nij/178919.pdf

[5] Agboola, T. (1997) The Architecture of Fear: A Pilot Study of Planning Urban Design and Construction Reaction to Urban Violence in Lagos, Nigeria. Ibadan IFRA and African Builders. In: Adedokun, O. and Atere, A., Eds., Crime Management in Nigeria, Lagos State University, Lagos, ix-x.

[6] Sahu, R. and Srivastava, P. (2004) Effective Crime Control using GIS. Map India Conference 2004 GIS development.net. http://gisdevelopment.net/application/military/defence/mi04184.htm

[7] Nelson Lew (1999) GIS: The Powerful Weapon for Law Enforcement. ESRI Arcuser Magazine Jan-March 1999. Environment Systems Research Institute Inc., ESRI. www.esricom

[8] Mishra, S. (2003) GIS in Homeland Security: An Indian Perspective Additional Directorate General. Information Sys- 
tems Army Headquarters.

[9] Andreas, M.S. (1997) Spatial Analysis of Crime Using GIS-Based Data: Weighted spatial Adaptive filtering and Chaotic Cellular Forecasting with Application to Street Level Drug Markets. Ph.D. Dissertation, H. John Heinz III School of Public Policy and Management Carnegie Mello University.

[10] Green, L.A. (1993) Drug Nuisance Abatement, Offender Movement Patterns, and Implications for Spatial Displacement Analysis. In: Block, C.R. and Dabdoub, M., Eds., Workshop on Crime Analysis through Computer Mapping Proceedings, Illinois Criminal Justice Information Authority, Chicago, 21-32.

[11] Cohen, J., Gorr, W.L. and Olligschlaeger, A.M. (1993) Modeling Street-Level Illicit Drug Markets. Working Paper \#93-64, H. John Heinz III School of Public Policy and Management, Carnegie Mellon University, Pittsburgh.

[12] Phillips, P.D. (1972) A Prologue to the Geography of Crime. Proceedings of the Association of American Geographers, 4, 86-91.

[13] Coker, R.O. (2004) Geospatial Information System Application to Security Situation Analysis for Efficient Policing: A Case Study of Mushin Local Government Area in Lagos State. Unpublished PGD Project, RECTAS, OAU Campus, Ile-Ife.

[14] Bowers, K.J., Johnson, S.D. and Pease, K. (2004) Prospective Hotspotting: The Future of Crime Mapping. British Journal of Criminology, 44, 641-658.

[15] Frisbie, D.W., Fishbine, G., Huntz, R., Joelson, M. and Nutter, J.B. (1977) Crime in Minneapolis: Proposals for Prevention. Community Crime Prevention Project, Governor's Commission on Crime Prevention and Control, St Paul.

[16] Date, C.J. (1994) Relational Database Writings 1991-1994. Addison-Wesley 1995, Boston, I-XVIII, 1-542.

[17] de By, R.A. and Janssen, L.L.F. (2001) Principles of Remote Sensing and Geographic Information Systems on CDROM. ITC, Enschede.

[18] Kufoniyi, O. (1995) Spatial Coincidence Modeling Automated Database Updating and Data Consistency in Vector GIS. ITC Publication Number 28 and PhD Thesis, Department of GIS and Remote Sensing, Wageningen Agricultural University, Netherlands, 206.

[19] Kelvin, L., Li, J., Chan, S.C.-F. and Ng, V.T.Y. (2009) An Application of the Dynamic Pattern Analysis Framework to the Analysis of Spatial-Temporal Crime Relationships. Journal of Universal Computer Science, 15, 1852-1870. 
Scientific Research Publishing (SCIRP) is one of the largest Open Access journal publishers. It is currently publishing more than 200 open access, online, peer-reviewed journals covering a wide range of academic disciplines. SCIRP serves the worldwide academic communities and contributes to the progress and application of science with its publication.

Other selected journals from SCIRP are listed as below. Submit your manuscript to us via either submit@scirp.org or Online Submission Portal.
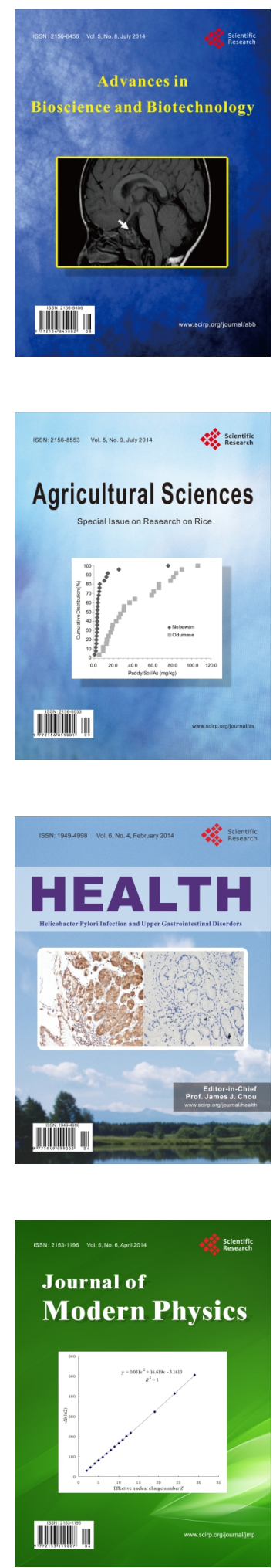
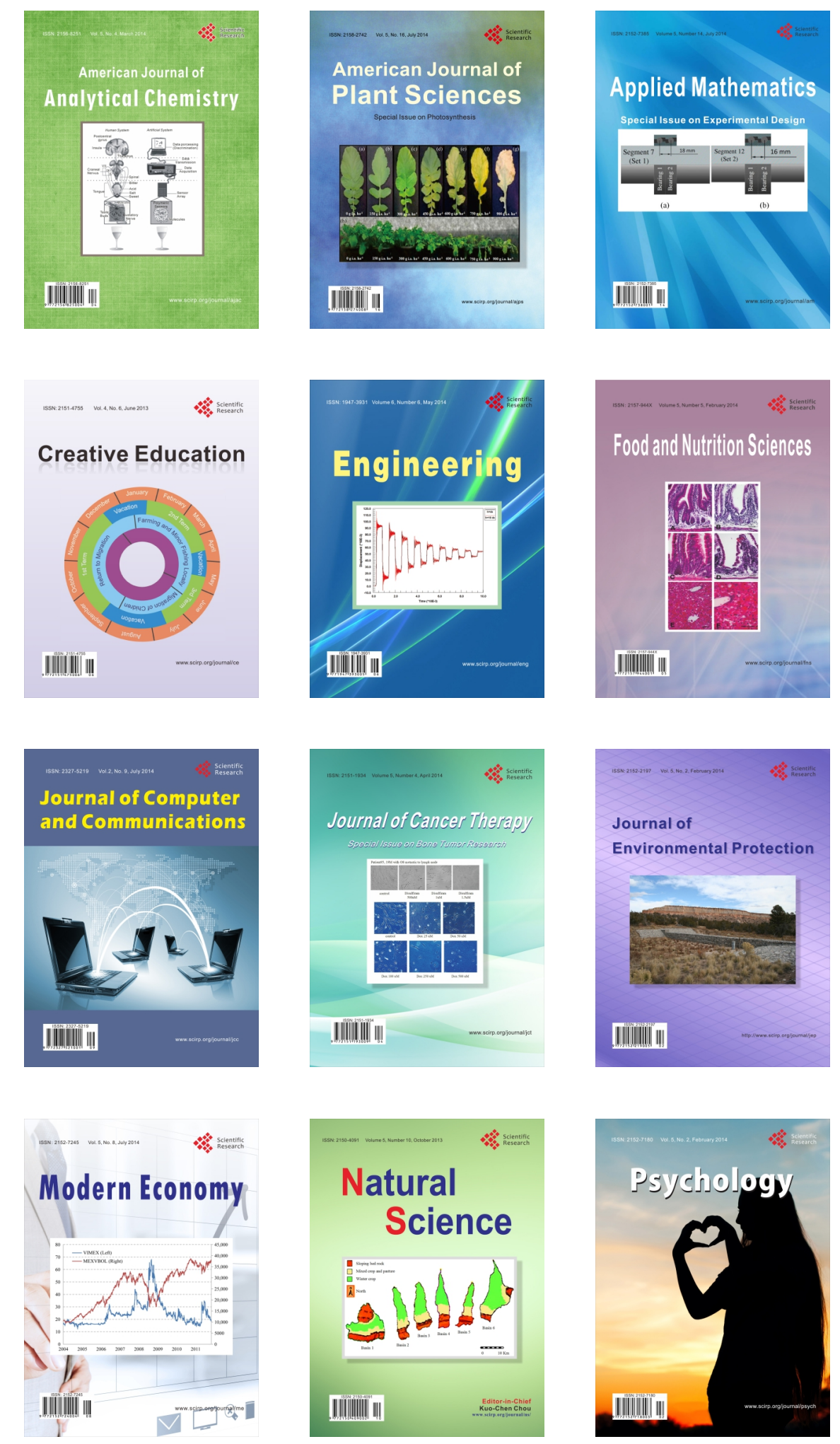